\title{
ARSENIC IN THE TREATMENT OF CHOREA.
}

\author{
BY \\ STANLEY Gं̈AHAM, M.D.,
}

(From the Medical Department, Royal Hospital for Sick Children, Glasgow.)

Arsenic has been used in the treatment of chorea for more than a century with results which are generally considered to have established its usefulness. In 1918, Osler ${ }^{1}$ stated that "with the exception of arsenic no remedy seems to have any influence in controlling the progress of the affection." There would seem, however, to prevail great difference of opinion regarding the dosage, some authors recommending large doses and others small.

In $1813 \mathrm{Martin}^{2}$, when he originally suggested the use of the drug, advised starting with a dose of five minims of Fowler's solution thrice daily, and increasing the dose by one minim daily until signs of intolerance appeared, when it should be stopped. Murray ${ }^{3}$, in 1899, recommended large doses from the beginning, namely, fifteen minims thrice daily, to be continued for a week. $\mathrm{Jacobi}^{4}$, who also favoured large doses, believed that the cause of failure on the part of arsenic could generally be ascribed to insufficient dosage. In marked contrast to these views is that expressed by Langmead ${ }^{5}$ in 1913 who said that arsenic should not be employed because of the bad effects often seen.

It is generally admitted that one of the serious disadvantages to the use of arsenic by mouth is the tendency of the drug to cause vomiting. Hence the administration by the subcutaneous route has been occasionally carried out. Radcliffe ${ }^{6}$ must have been one of the first to practice this method which he described in Reynold's System of Medicine in 1872. This route of administration has the great drawback that it causes considerable local irritation and thus was found to be unsuitable for children.

With the advent of the organic arsenical preparations, and the possibility of their introduction by the intravenous route, it was only natural that they should be employed in the treatment of chorea in the hope that, in this way, local irritation could be avoided and at the same time much larger amounts of arsenic safely given. Many authors have reported examples of chorea treated by arsenic intravenously. Bokay? , in Budapest, has probably been the most enthusiastic supporter of the method which he first recommended in 1911. Recently ${ }^{8}$ he has again expressed his views in its favour, and records two cases in which the chorea had been present, in one for five weeks and in the other for four weeks ; in these, after the administration of $1.2 \mathrm{grm}$. and $1 \cdot 5$ grm. of neo-salvarsan, all movements disappeared in forty-three and thirtythree days respectively. In his original paper he gives no figures relative to results, and quotes only one case. In this patient the chorea had been in existence for one year, and disappeared in thirty-five days after the injection of 
$1.2 \mathrm{grm}$. of salvarsan. Moffett and Smith ${ }^{\circ}$ have still more recently commented on the treatment of nine cases with sulpharsphenamine, but merely state that in five definite clinical improvement resulted.

\section{Present Investigations.}

Reference to all the available records reveals wonderfully scant evidence of the value of arsenic intravenously in the treatment of chorea, and a complete absence of any actual comparison with cases treated by other methods. Since impressions are notoriously apt to be erroneous, it was deemed advisable to compare two series of cases treated synchronously, one with arsenic intravenously and the other with arsenic by the mouth. There is included for comparison a similar number treated by sodium salicylate though not during the same period. The arsenic was given intravenously in the form of neo-kharsivan at four-day intervals, and by the mouth as Fowler's solution in fifteen minim doses, thrice daily. In each case the drug was continued until all choreiform movements disappeared or until toxic signs supervened. The sodium salicylate was given in ten to twenty grain doses, with twice the amount of sodium bicarbonate, five times daily. Treatment was begun immediately after admission of the patient to hospital. The cases were not selected in any way, and other therapeutic factors were common to all groups, the patients being confined to bed in the recumbent position and receiving full hospital diet.

The average amount of neo-kharsivan administered was $2.15 \mathrm{grm}$. (containing 0.465 grm. arsenic), three cases being given $3 \cdot 15$ grm., $3 \cdot 6$ grm. and 3.9 grm. each within a period of thirty days. In four of the cases signs of intolerance in the form of a skin rash appeared, but in only one of these was it severe. These toxic symptoms did not occur in any of those cases receiving the largest doses, a fact which supports the usual teaching that the size of the dose per se is not responsible for such manifestations, but rather some idiosyncrasy on the part of the patient. Of the fifteen cases treated, ten had cardiac murmurs on admission, and ten on dismissal three months later. In two, the cardiac murmur disappeared, and in two others murmurs appeared.

The average amount of Liquor arsenicalis given was 11.5 drachms (containing $0.276 \mathrm{grm}$. arsenic). This corresponds to only a little more than half the amount of arsenic which the patients in the neo-kharsivan group were receiving during approximately the same time. Two children presented signs of intolerance, one a neuritis and one a rash. Both cleared up speedily when the drug was discontinued. Seven patients had cardiac murmurs on admission, and only four on dismissal.

In the last group the salicylate of sodium was administered throughout the stay in hospital. None of the children showed any signs of intolerance. Eight patients had cardiac murmurs on admission, and nine on dismissal three months later.

In all, the results of the treatment of 45 cases are available for analysis, there being 15 cases in each group. Each group was further sub-divided as follows, 
(a) Cases in which the chorea had been present less than thirty days before admission.

(b) Cases in which the chorea had been present from thirty to sixty days before admission.

(c) Cases in which the chorea had been present from sixty to ninety days before admission.

Table Showing Results of Treatment in Chorea.

\begin{tabular}{l|c|c|c|c}
\hline $\begin{array}{c}\text { No. of } \\
\text { cases. }\end{array}$ & $\begin{array}{c}\text { Average duration } \\
\text { in days of } \\
\text { chorea previous } \\
\text { to admission. }\end{array}$ & $\begin{array}{c}\text { Average duration } \\
\text { in days of } \\
\text { chorea after } \\
\text { admission. }\end{array}$ & $\begin{array}{c}\text { Average total } \\
\text { duration of } \\
\text { chorea } \\
\text { in days. }\end{array}$ \\
\hline
\end{tabular}

(A.) Cases treated with Neo-kharsivan.

\begin{tabular}{|c|c|c|c|c|}
\hline $\begin{array}{l}\text { (a) } 0-30 \text { days .. } \\
\text { (b) } 30-60 \quad, \quad . \\
\text { (c) } 60-90 \quad \text {, }\end{array}$ & $\begin{array}{l}6 \\
5 \\
4\end{array}$ & $\begin{array}{l}18 \\
41 \\
75\end{array}$ & $\begin{array}{l}36 \\
62 \\
32\end{array}$ & $\begin{array}{r}54 \\
103 \\
109\end{array}$ \\
\hline
\end{tabular}

(B.) Cases treated with Liq. Arsenicalis.

\begin{tabular}{rrr|rr|r|r|r}
\hline (a) $0-30$ & days.. & 11 & 16 & 32 & 48 \\
(b) $30-60$ & \% & $\ldots$ & 4 & 45 & 28 & 73 \\
(c) $60-90$ & , & $\ldots$ & - & - & - & - \\
\hline
\end{tabular}

(C.) Cases treated with Sod. Salicylate.

\begin{tabular}{|c|c|c|c|c|}
\hline 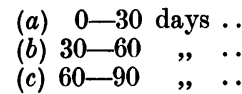 & $\begin{array}{r}9 \\
6 \\
-\end{array}$ & $\begin{array}{l}17 \\
37 \\
-\end{array}$ & $\begin{array}{l}26 \\
30 \\
-\end{array}$ & $\begin{array}{l}43 \\
67 \\
-\end{array}$ \\
\hline
\end{tabular}

(a) Chorea present for less than 30 days before admission.

(b) " " $\quad 30-60 \quad$ " $\quad$ " $60-90 \quad$ "

The results are summarized in the accompanying table. It is perhaps unfortunate that in some of the cases treated with neo-kharsivan (Group A), the chorea should have existed longer before coming under observation than was the case in the other two groups. However, even if one looks upon chorea as a self-limited disease, then the cases in Group A should have cleared up more quickly than those in the other groups, but this did not occur. Generally speaking, arsenic intravenously, although given in larger doses, seems to be less efficacious than liquor arsenicalis by mouth, and both of these measures less efficacious than sodium salicylate. Regarding the cardiac condition at the end of the stay in hospital, those in Group B (i.e., cases treated with arsenic by the mouth), show the best results.

In searching for a reason why cases treated with arsenic intravenously, although given relatively much larger amounts of arsenic, should take longer to clear up than those receiving liquor arsenicalis per os, one cannot avoid thinking that no matter how easily venipuncture is performed, a certain apprehension on the part of the patient is bound to exist, and it may well be that the slight additional emotional strain is responsible for the longer duration of the chorea. One must also remember that those patients receiving arsenic by the mouth three times daily are undoubtedly more constantly under the influence of the drug than are those who receive a massive dose intravenously 
every fourth day. In any case, one is inclined to doubt the statement that the improvement in chorea is proportionate to the amount of arsenic given. The numbers under consideration are admittedly small, but in every sub-group except one (the 30 to 60 day period in Group A), the chorea disappeared in twenty-six to thirty-six days after admission to hospital. Generally speaking, the chorea disappeared in practically the same time after admission to hospital irrespective of drug treatment.

Although drug therapy would, then, appear to be of no value, the fact that chorea is a manifestation of the rheumatic infection suggests the advisability of giving salicylates. One does not infer, of course, that sodium salicylate is a specific for rheumatism, but of its value in some of the manifestations of rheumatism there can be no question, and because it may inhibit recurrences I consider its administration in chorea advisable.

\section{Conclusions.}

1. The course of chorea would not appear to be influenced by treatment with arsenic. The improvement, if any, probably results from its tonic action and is not in proportion to the amount of arsenic given. Intravenous arsenic has no advantages.

2. Rest in bed and freedom from emotional disturbances will usually cause a disappearance of chorea in four or five weeks.

3. The administration of sodium salicylate is recommended in the hope that it might have some good effect on the rheumatic infection.

\section{REFERENCES.}

1. Osler, W., Prin. and Pract. of Med., Lond., 8th Ed., 1915, 1073.

2. Martin, T., quoted by Radcliffe, C. (see below).

3. Murray, W., Rough Notes on Remedies, 3rd Ed., 1899, 16.

4. Jacobi, A., Therapeutics of Inf. and Childhood, Philad. and Lond., 3rd Ed., 1903, 298.

5. Langmead, F., Brit. Med. J., Lond., 1913, i, 1261.

6. Radcliffe, C., Reynold's Syst. of Med., Lond., 1872, II, 212.

7. Bokay, J., Deut. Med. Wchschr., Berlin, 1911, XXXVII, 111.

8. Bokay, J., Ergeb. d. inn. Med. u. Kinderheill, Berlin, 1923, XXIV, 1.

9. Moffett, R., \& Smith, C., Arch. Ped., N.Y, 1924, XLI, 657. 